\title{
LAND USE AND LAND COVER MAPPING - A CASE STUDY OF AHMEDABAD DISTRICT
}

\author{
Darshana Rawal ${ }^{1}$, Abha Chhabra ${ }^{2}$, Mehul Pandya ${ }^{2}$, Anjana Vyas ${ }^{1}$ \\ ${ }^{1}$ Center for Applied Geomatics, CRDF, CEPT University, Ahmedabad, Gujarat, India. \\ ${ }^{2}$ Space Applications Centre, ISRO, Ahmedabad, Gujarat, India.
}

Commission III, WG III/1

KEY WORDS: Land Use Land Cover, LISS-IV, Image Classification, Ahmedabad

\begin{abstract}
:
Land cover mapping using remote-sensing imagery has attracted significant attention in recent years. Classification of land use and land cover is an advantage of remote sensing technology which provides all information about land surface. Numerous studies have investigated land cover classification using different broad array of sensors, resolution, feature selection, classifiers, Classification Techniques and other features of interest from over the past decade. One, Pixel based image classification technique is widel y used in the world which works on their per pixel spectral reflectance. Classification algorithms such as parallelepiped, minimum distance, maximum likelihood, mahalanobis distance are some of the classification algorithms used in this technique. Other, Object based image classification is one of the most adapted land cover classification technique in recent time which also considers other parameters such as shape, colour, smoothness, compactness etc. apart from the spectral reflectance of single pixel.
\end{abstract}

At present, there is a possibility of getting the more accurate information about the land cover classification by using latest technology, recent and relevant algorithms according to our study. In this study a combination of pixel-by-pixel image classification and object based image classification is done using different platforms like ArcGIS and e-cognition, respectively. The aim of the study is to analyze LULC pattern using satellite imagery and GIS for the Ahmedabad district in the state of Gujarat, India using a LISS-IV imagery acquired from January to April, 2017. The over-all accuracy of the classified map is $84.48 \%$ with Producer's and User's accuracy as $89.26 \%$ and $84.47 \%$ respectively. Kappa statistics for the classified map are calculated as 0.84 . This classified map at 1:10,000 scale generated using recent available high resolution space borne data is a valuable input for various research studies over the study area and also provide useful information to town planners and civic authorities. The developed technique can be replicated for generating such LULC maps for other study areas as well.

\section{INTODUCTION}

Land use/ Land cover (LULC) plays an important role in global climate as well as topographic change. Some natural devastations like deforestation, bio-diversity loss, global warming, increase in natural disaster-flooding etc. resulted from human/natural modifications are often related to land cover changes. Therefore, available data on LULC changes can provide critical input to decision-making of environmental management and planning the future. The changes in LULC are unplanned and uncontrolled due to the pressure resulting from population growth and increasing socio-economic necessities. The changes are generally caused by lack of proper management of agriculture, urban, vegetation, forest lands etc. which leads to severe environmental problems.

The spatial distribution of land use/ land cover changes over a large area can be studied using Remote Sensing techniques and Geographic Information Systems. Many organizations and institutions from all over the world have undertaken the studies in past as well as present concentrating on the applications of LULC changes. GIS provides a flexible environment for collecting, storing, displaying and analyzing spatial data and Remote sensing imagery is one of the important data resources of GIS providing high resolution satellite imagery. The rich data collection and the spectral resolution of satellite imagery are the most important reason for their use in such type of studies. The change detection process is done to recognize the change in LULC over a period of time. Many techniques are developed like post-classification comparison, conventional image differentiation, image ratio, image regression and manual on-screen digitization etc. A variety of studies have used different methods of classification and came out with different accuracies but post classification comparison was found out to be most accurate procedure as from the literature. Multi-temporal mapping applying remote sensing and the Geographical Information System (GIS) are particularly useful for land use management and environmental studies. Frequently updated land use land cover information is essential to many socio-economic and environmental applications, including urban and regional planning, natural resources conservation and management, etc. (Homer et al., 2007; Lu and Weng, 2007; Jensen, 2009). Historically, aerial photographs have been an important source of land use information (Bauer et al., 2003). In past few decades maps have been created using old traditional methods such as digitization, scanning, ground surveying methods etc. Such methods are still in use at some places (Kamagata et al., 2006). Land use / Land Cover mapping methods have become more advanced and more informative with high resolution dataset in recent time period. These methods are dependent on images interpretation and ground survey. These and other related problems prompt many potential users remain sceptical about the capabilities of remote sensing data (Rowlands and Lucas, 2004). Remote 
sensing data are more uniform than ancillary data, which vary in data format, accuracy, spatial resolution, and coordinate systems (Lu and Weng, 2007). Aim is to improve the understanding of methods, their processing and technique for spatial distribution over Ahmedabad district of Gujarat state located in western India.

Various classification approaches that have been developed and widely used to produce land cover maps. They range in logic, from supervised to unsupervised; parametric to nonparametric to non-metric, or hard and soft (fuzzy) classification, or per-pixel, sub-pixel, and profiled (Keuchel et al.. 2003, Jensen 2005). However, there are two Traditional types of classification procedure and each of these types finds application in the processing of remote sensing images: one is referred to as supervised classification and the other one is unsupervised classification. These can be used as alternative approaches, but are often combined into hybrid methodologies using more than one method (Richards and Jia, 2006) but Object-oriented image classification methods provide a promising tool for mapping detailed land cover (Mori et al., 2004).

\section{OBJECTIVE}

The objective of the present study is to generate a high accuracy land use/cover classification map for Ahmedabad district located in the state of Gujarat, India using recent period high resolution data. To the best of our knowledge, such classified map of the recent period derived from high resolution satellite data has not been attempted. The available maps are quite old. In the current time of rapid urbanisation and changing landuse patterns, such input is essentially required for several studies.

\section{STUDY AREA}

The study is proposed over Ahmedabad district of Gujarat state (Figure 1). Ahmedabad is an urban, densely populated industrialized largest city in the central part of the Gujarat in Western India. Ahmedabad is divided by River Sabarmati into two physically distinct Eastern and Western regions. Ahmedabad district comprises of 11 talukas surrounding the Ahmedabad city which includes Ahmedabad City, Barwala, Bavla, Daskroi, Detroj-Rampura, Dhandhuka, Dholka, Mandal, Ranpur, Sanand and Viramgam. According to 2011 census, Ahmedabad district ranks 8th among the 640 districts with a total population of $7,045,314$. The municipal area is under the jurisdiction of the Ahmedabad Municipal Corporation (AMC) which covers an area of $466 \mathrm{sq}$. $\mathrm{km}$. The total area of Ahmedabad district is 7,170 sq. kms.

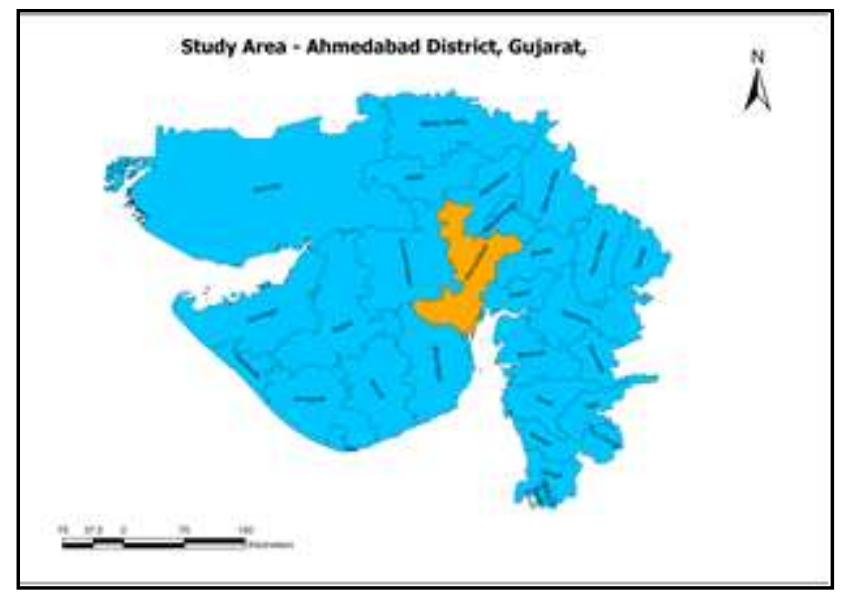

Figure 1 Study Area of Ahmedabad district
The urban and peri-urban regions of Ahmedabad are characterized with diverse microenvironments viz. rural areas in West, densely populated urban conglomerates in West and Central regions, industrial regions in the Central and East Ahmedabad. The study area of Ahmedabad is shown in Figure. 1 .

Ahmedabad district is located in western part of India in Gujarat State surrounded by Mehsana and Gandhinagar districts to the north, Kheda and Anand districts to the east, The Gulf of Khambhat, Botad and Bhavnagar districts to the south and Surendranagar district to the west. Main city of this District is Ahmedabad.

\section{METHODOLOGY}

The methodology adopted for the study is based on Level -II Standard Land Use/Cover Classification (NRSC, 2012). Multitemporal, multispectral IRS Resourcesat-2 LISS-IV data for the recent period 2017 was used for the study. The various steps included satellite database preparation, image classification, interpretation (on-screen visual), ground truth collection, validation, map finalization, quality checking of final maps and accuracy assessment. The flowchart of the methodology is given in Fig 2.

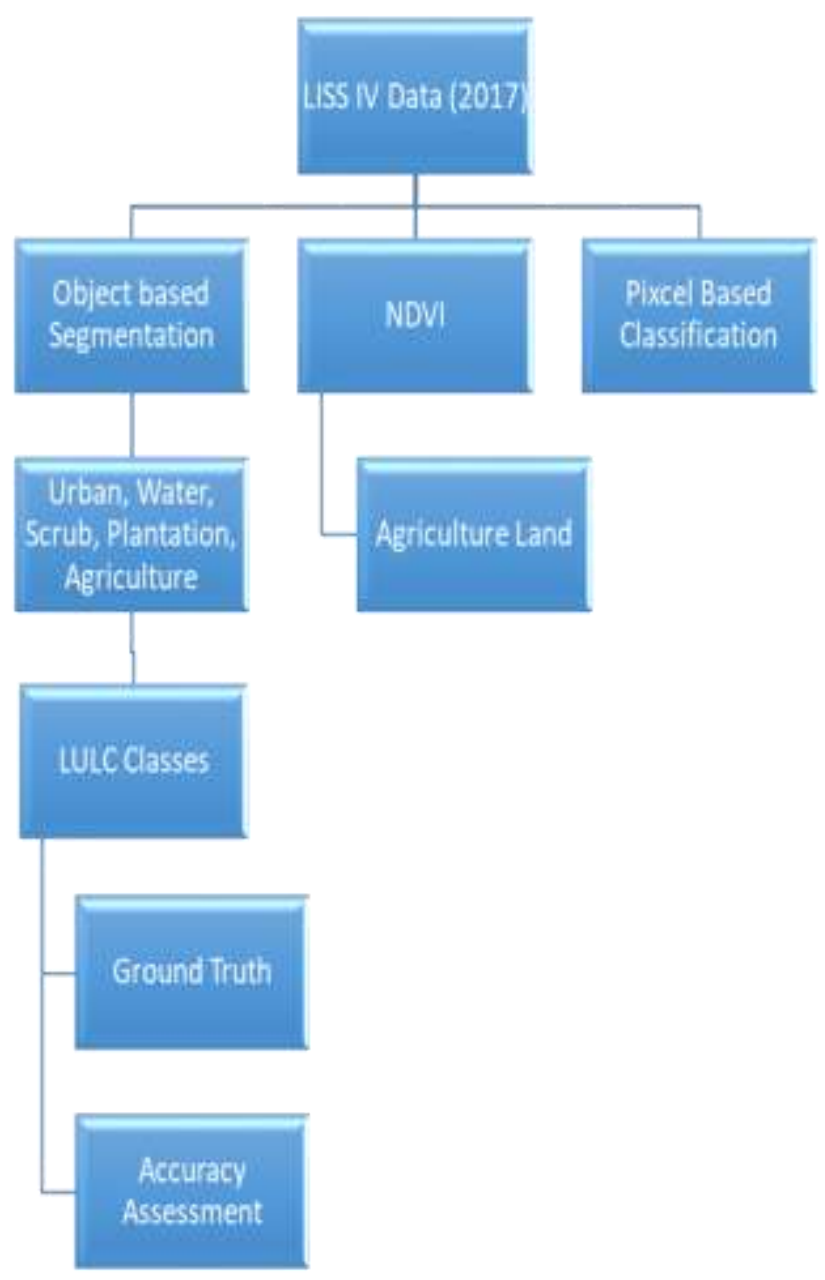

Figure 2. Flowchart - Methodology 


\section{SATELLITE DATA ANALYSIS}

The pre-processing and post image processing and analysis were carried out to enhance the quality of the images and the readability of the features LISS IV data sets were geometrically corrected and the projection was set to Universal Transverse Mercator (UTM) projection system, zone 43. The spheroid and datum was referenced to WGS84. All the images were geometrically co-registered to each other using ground control points into UTM projection with geometric errors of less than one pixel, so that all the images have the same coordinate system.

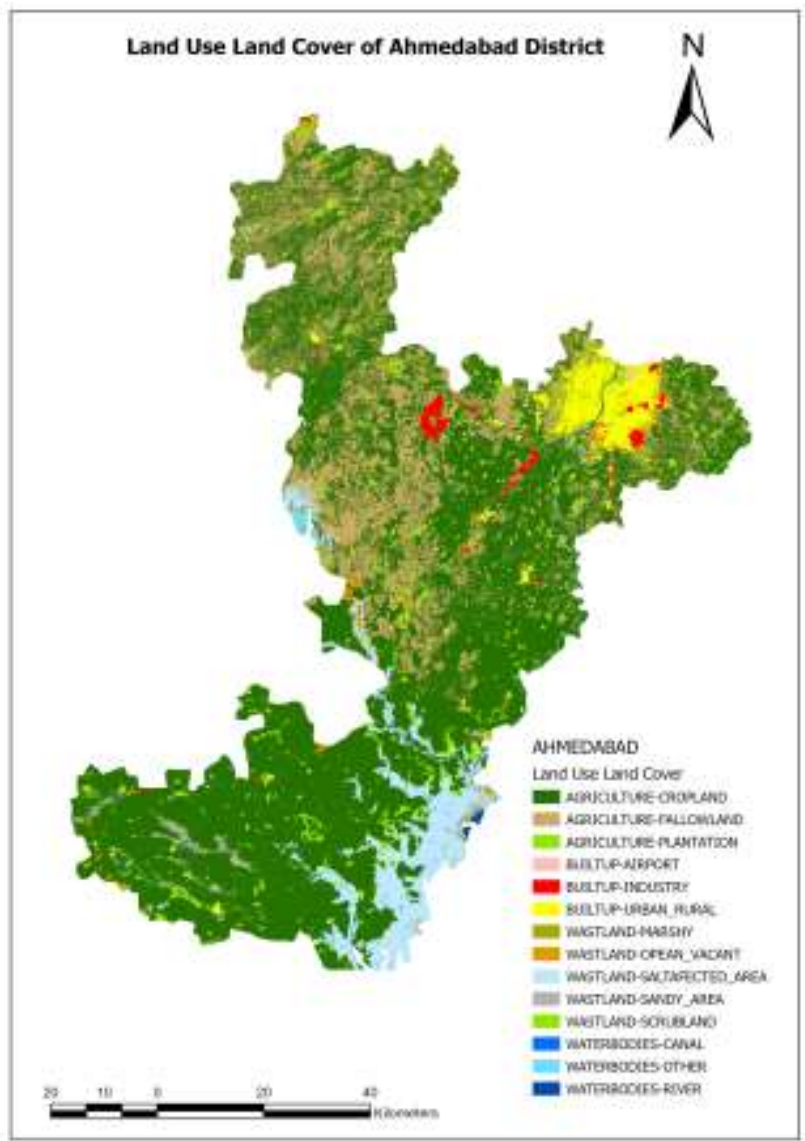

Figure 3. Classified map of Ahmedabad district

Classification Procedure: Different algorithms viz., Nearest neighbourhood for object based classification was carried out in eCognition Developer s/w, maximum-likelihood supervised classification technique for pixel based classification, NDVI and TGI for vegetation extraction has been combine used in the present study for the better accuracy. The object-oriented approaches were used for mapping detailed land uses. This approach considers group of pixels and the geometric properties of image objects.

It segments the imageries into homogenous regions based on eighbouring pixels spectral and spatial properties. Thus, an object oriented method has also been applied in this project in to avoid the mixed pixel problems. The Normalized Difference Vegetation Index (NDVI) is a standardized index which gives a capability to generate image shows vegetation (relative biomass). NDVI ranges between -1 to 1 . For this study NDVI is used to generate croplands and the NDVI values within the limits 0.4 to 0.9 are considered. Land Use / Cover classes generated from above mentioned three algorithms has been combined to generate the accurate Land Use/Cover classified map of the study area.

5.1 LAND COVER CLASSES: The land cover classes followed in this project are adopted from 'The Description and Classification of Land use Land cover' by National Remote Sensing Centre, Department of Space, Government of India. The Classification System has been developed such that all departments in the Country maintain consistency in generating land use statistics at District, State and National level.

5.2 GROUND TRUTH: Field survey was performed throughout the study area using Global Positioning System (GPS). This survey was performed in order to obtain accurate location point data for each LULC class included in the classification scheme as well as for the creation of training sites and for signature generation. Ground truth points are collected generously using the GPS and also corroborated with the high resolution data. The distribution of GT points in the study area.

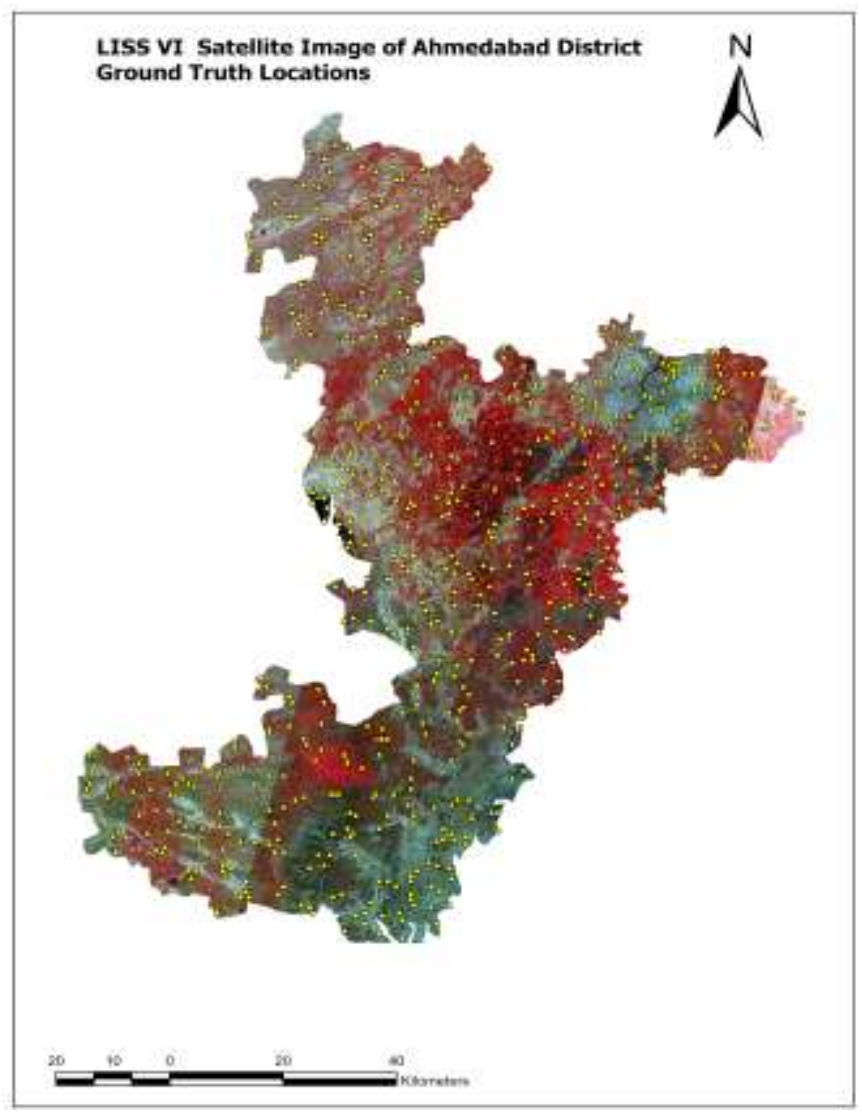

Figure 4. Distribution of Ground truth points on FCC of LISS-IV data

\subsection{ASSESSMENT OF CLASSIFICATION RESULTS USING ERROR MATRIX:}

The error matrix-based accuracy assessment method is the most common and valuable method for the evaluation of change detection results. Thus, an error matrix and a Kappa 
analysis were used to assess change accuracy, Kappa analysis is a discrete multivariate technique used in accuracy assessments (Congalton and Mead, 1983; Jensen, 1996).
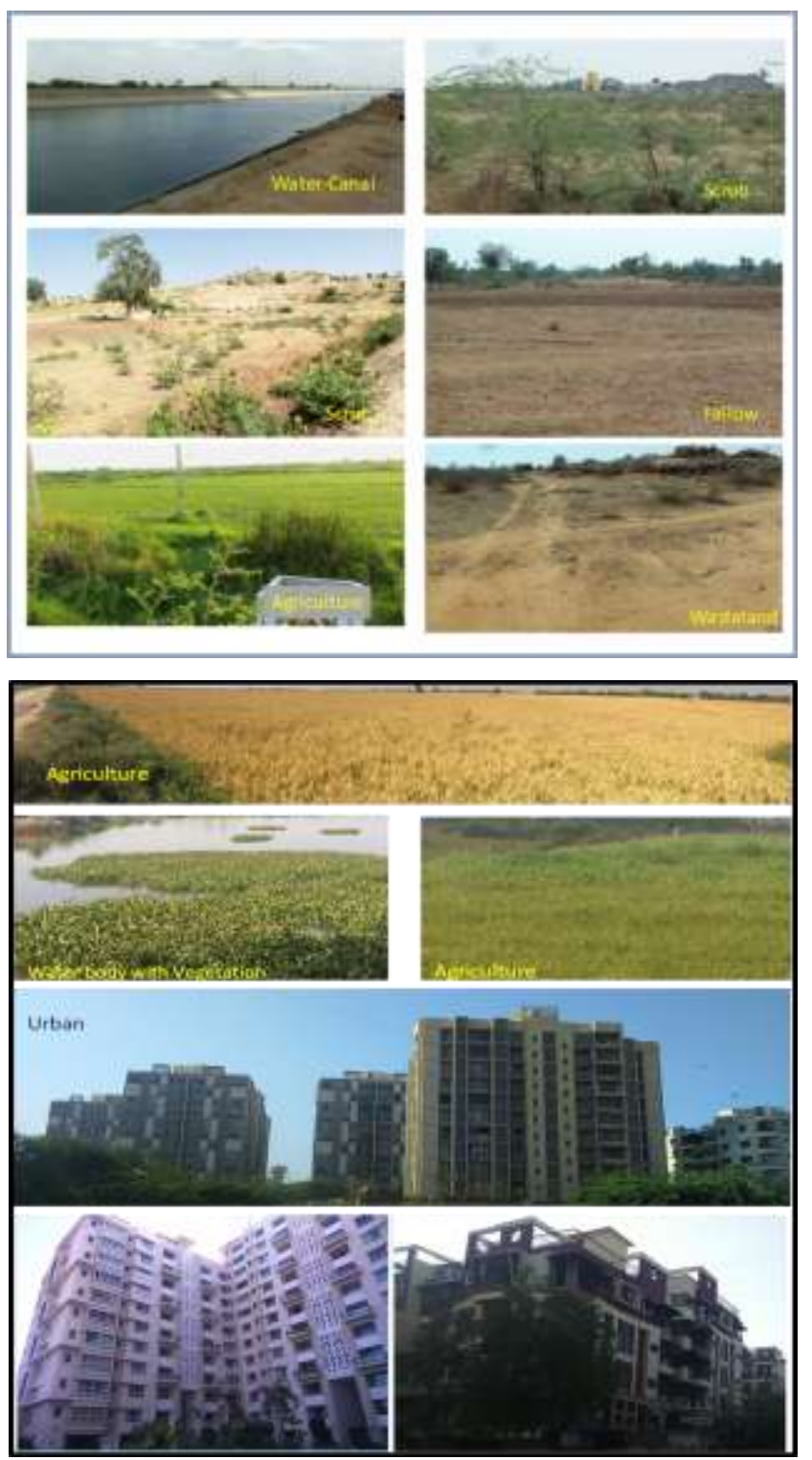

Figure 4. Ground Truth of various LULC FCC of LISS-IV data

\section{RESULTS AND DISCUSSION}

Tabulations and area calculations provide a comprehensive data set in terms of the overall landscape. Graphical representations of the overall pixel counts offer a general insight into the relative amounts of the defined classes across the landscape. Accuracy assessment is an important parameter used to evaluate classification performance and usefulness of the output. It expresses the degree of correctness of a map or classification in comparison with actual ground features. Accuracy assessment in terms of class specific producer's and user's accuracy, overall accuracy and Kappa coefficient are subsequently computed after generating confusion matrix.

The outcome of the data processing and analysis were presented in form of digital maps, layout and attribute tables. The area covered by the land cover map of Ahmedabad district for the year 2017 is shown in Table 1 and Figure 5. FCC and
Classified Map of Ahmedabad district is shown in Figure 6 and 7 respectively. Table shows the accuracy of the assessment in terms of average User's Accuracy, average Producer's Accuracy and Overall Accuracy. Table 3 shows the class wise Kappa statistics of the study area. The final classification product provides an overview of the major LULC features of Ahmedabad district for the year 2017.

\begin{tabular}{|c|c|c|c|}
\hline Land Use/Cover Classes & $\begin{array}{l}\text { AREA in sq } \\
\mathrm{km}\left(10^{3}\right)\end{array}$ & $\begin{array}{l}\text { AREA in sq } \\
\mathrm{km}(103)\end{array}$ & Area (\%) \\
\hline BUILTUP-AIRPORT & 36.24 & \multirow{3}{*}{3757.08} & \multirow{3}{*}{4.85} \\
\hline BUILTUP-INDUSTRY & 709.33 & & \\
\hline BUILTUP-URBAN_RURAL & 3011.51 & & \\
\hline WATERBODIES-CANAL & 92.53 & \multirow{3}{*}{990.01} & \multirow{3}{*}{1.28} \\
\hline WATERBODIES-RIVER & 391.12 & & \\
\hline WATERBODIES-OTHER & 506.36 & & \\
\hline AGRICULTURE-FALLOWLAND & 13070.18 & \multirow{3}{*}{63538.94} & \multirow{3}{*}{82.09} \\
\hline AGRICULTURE-CROPLAND & 50063.63 & & \\
\hline AGRICULTURE-PLANTATION & 405.12 & & \\
\hline WASTLAND-SCRUBLAND & 2916.69 & 2916.69 & 3.77 \\
\hline WASTLAND-SALTAFECTED_AREA & 4669.61 & \multirow{4}{*}{6194.48} & \multirow{4}{*}{8.00} \\
\hline WASTLAND-MARSHY & 238.95 & & \\
\hline WASTLAND-OPEAN_VACANT & 531.78 & & \\
\hline WASTLAND-SANDY_AREA & 754.13 & & \\
\hline
\end{tabular}

Table 1. Statistics of different LULC classes for Ahmedabad district FCC of LISS-IV data

The over-all accuracy of the classified map is $84.48 \%$ with Producer's and User's accuracy as $89.26 \%$ and $84.47 \%$ respectively. Kappa statistics for the classified map are calculated as 0.84 .

\begin{tabular}{|l|l|r|}
\hline S.No & \multicolumn{1}{|c|}{ LULC Classes } & $\begin{array}{l}\text { Kappa } \\
\text { Coefficient }\end{array}$ \\
\hline 1 & AGRICULTURE-CROPLAND & 0.77 \\
\hline 2 & WASTLAND-SCRUBLAND & 0.84 \\
\hline 3 & BUILTUP-INDUSTRY & 0.84 \\
\hline 4 & WASTLAND-SALTAFECTED & 0.84 \\
\hline 5 & AGRICULTURE-FALLOWLAND & 0.84 \\
\hline 6 & BUILTUP-URBAN_RURAL & 0.84 \\
\hline 7 & WASTLAND-SANDY_AREA & 0.84 \\
\hline 8 & WATERBODIES-OTHER & 0.84 \\
\hline 9 & WASTLAND-OPEAN_VACANT & 0.84 \\
\hline 10 & WATERBODIES-RIVER & 0.84 \\
\hline 11 & AGRICULTURE-PLANTATION & 0.84 \\
\hline 12 & WASTLAND-MARSHY & 0.84 \\
\hline 13 & WATERBODIES-CANAL & 0.84 \\
\hline 14 & BUILTUP-AIRPORT & $\mathbf{0 . 8 4}$ \\
\hline & Overall Kappa Statistics & \\
\hline
\end{tabular}

Table 2. Kappa Statistics of Landuse Landcover lassification

he classification result shows that LULC classes have been successfully classified with overall classification accuracy of $84.48 \%$. More than $80 \%$ classification accuracy, in terms of producer's accuracy, is achieved for all the classes except 
Scrub and Fallow land. 100\% accuracy is obtained in water class and also in Urban-Airport and Urban Plantation classes. The LULC map has been generated at 1: 10,000 scale using Resourcesat-2 LISS IV high resolution multi-temporal datasets. This map is based on the standard methodology adopted for generating LULC maps at district level hence it would be a very useful input to several research studies over the study area. This map generated under the current research project is a valuable input for designing an Air Quality field sampling plan and developing standard protocols.

\section{ACKNOWLEDGEMENTS}

This study has been carried out as a part of SAC-CEPT collaborative project "Urban Air Quality Assessment using Remote Sensing and GIS" under SHRESTI programme of SAC, ISRO. Authors are thankful to Shri D. K. Das, Director, SAC, Dr. Rajkumar DD, EPSA and Dr. B. K. Bhattacharya, Head AED/EPSA for their support during the course of this study.

\section{REFERENCES:}

Bauer, M.E, Yuan, F. \& Saway, K.E., 2003 - Multi-temporal Landsat image classification and change analysis of land cover in the Twin Cities(Minnesota) Metropolitan Area. Second int. workshop on the Analysis of multi-temporal remote sensing images, Italy, pp. 1-8.

Congalton R.G. Oderwald R.G. Mead R.A.1983 Assessing Landsat classification accuracy using discrete multivariate analysis statistical techniques.

Homer C., Dewitz J., Fry J., Coan M., Hossain N., Larson C., Herold N., McKerrow A., VanDriel J.N., Wickham J., 2007 Completion of the 2001 National Land Cover Database for the Conterminous United States. Photogrammetric Engineering and Remote Sensing, 73: 337-341.

Jensen J.R., 2009 - Remote Sensing of the Environment: An Earth Resource Perspective 2/e. Pearson Education India.

Jensen, J., 2005 - "Introductory Digital Image Processing, 3rd edition".

Kamagata, N., Hara, K., Mori, M., \& Akamatsu, Y., 2006 - A new method of vegetation mapping by object-based classification using high resolution satellite. http://www.commission4.isprs.org/obia06/Papers/06_Automate d

Keuchel, J., Naumann, S., Heiler, M. \& Siegmund, A., 2003 "Automatic land cover analysis for Tenerife by supervised classification using remotely sensed data", Remote Sensing of Environment, vol. 86, no. 4, pp. 530-541.

Lu D., Weng Q., 2007 - Survey of Image Classification Methods and Techniques for Improving Classification Performance. International Journal of Remote Sensing, 28: 823-870. doi: http://dx.doi.org/10.1080/01431160600746456.

Mori, M., Hirose, Y., Akamatsu, Y. and Li, Y., 2004 - Objectbased classification of IKONOS data for rural land use mapping.

http://www.isprs.org/istanbul2004/comm3/papers/305.pdf.
NRSC, 2012, Manual of National Land Use/Land Cover Mapping (Second Cycle) using Multi-Temporal Satellite Data, Department of Space, Hyderabad.

Richards, J.A. \& Jia, X., 2006 - Remote sensing digital image analysis: an introduction, Springer Verlag.

Rowlands, A.P. \& Lucas, R.M.,2004 - Use of Hyperspectral data for supporting the classification of agricultural land and semi-natural vegetation using multi-temporal satellite data. Proc. of the airborne imaging spectroscopy workshop, Bruges, pp. 1-5. 